\title{
Knowledge, attitude and determinants of breastfeeding among ante-natal women at a teaching hospital at Wayanad, Kerala: A cross-sectional study
}

\author{
K. A. Manoj Narayana ${ }^{1}$, Arun T. Mithrason ${ }^{2 *}$, Vijatha Thomas ${ }^{3}$ \\ ${ }^{1,3}$ Associate Professor, ${ }^{1}$ Dept. of Paediatrics, ${ }^{3}$ Dept. of Biochemistry ${ }^{2}$ Professor, Dept. of Community Medicine, DM WIMS \\ Medical College, Kerala University of Health Sciences, Thrissur, Kerala, India
}

*Corresponding Author:

Email: arunmithrason@gmail.com

\begin{abstract}
Introduction: Breastfeeding is best gift for child from mother. It is safe, adequate to fulfill nutrition in early life, provides with immunity for protection from various diseases. Exclusive breastfeeding is affected due to various cultural practices which exists, or, due to lack of knowledge of mother and other family members, or, because, mother has to return to work and doesn't have enough maternity leaves or proper feeding area in the workplace. The present study is done to assess knowledge and attitude of ante-natal women towards breastfeeding.

Material and Methods: 120 women who had come for routine ante-natal checkup to DM WIMS hospital, Wayanad, Kerala were included in the present study. A semi-structured questionnaire containing various aspects of breast feeding and basic information of the participants was used to assess the knowledge, attitude and find determinants of breast feeding.

Results: $55.8 \%$ participant were in the age group 18-25yrs. The mean age of study participant was 25.4 years. $50 \%$ of the participants were nulliparous, $30 \%$ primiparous and $20 \%$ were multiparous. $43.3 \%$ of the study participants knew the importance of breastfeeding and only $37.5 \%$ knew about colostrum. $93.3 \%$ participants considered breast milk healthier than artificial substitute like formula milk, etc. Majority of participants received information about breastfeeding from media (54\%) and doctors (41\%). $77 \%$ of participants said presence of strangers affect breastfeeding and $56 \%$ said crèche should be available at all work places. A significant association was seen between age and breastfeeding (p-value 0.003), and also between, age and knowledge of colostrum (p-value 0.002), in the present study. Association between parity and breastfeeding, and, parity and colostrum was also found to be significant in our study with p-value 0.001 and 0.007 respectively.

Conclusion: In the present we found that, mother's knowledge and attitude towards breastfeeding was favorable, but, still more efforts are required to reach WHO recommended prevalence of $90 \%$.
\end{abstract}

Keywords: Breastfeeding, knowledge, attitude, colostrum, Wayanad.

\section{Introduction}

The best gift from mother to her newborn is breast milk. It is not only nutritive but also protective. It also increases the emotional bonding between mother and infant. The World Health Organization (WHO) and United Nations Children's Fund (UNICEF) recommends that every infant should be exclusively breastfed for the first six months of life, and, it should be continued for up to two years of age or longer along with complementary food. ${ }^{1}$ Breastfeeding should be started immediately after birth. The first milk contains thick, yellow colored colostrum. It is rich in proteins, carbohydrates, vitamin A and sodium chloride, and, contains lower amounts of lipids, fat, and potassium than normal milk. ${ }^{2}$ It is best for newborns premature digestive system. In addition, it contains various immunoglobulin's like IgA (reactive to Escherichia coli virulence associated proteins) IgG, IgM and, various cytokines and growth factors., ${ }^{3,4}$ Thus, it can be considered as first vaccine for infant for his survival and to fight various infections.

One of the main cause of neonatal mortality and morbidity is inadequate breastfeeding due to lack of knowledge of mother regarding its importance and benefits. ${ }^{5}$ Worldwide as many as 4,000 infants and young children die because they are not breastfed within the first hour after birth. In many countries, infants are given liquids other than mother's milk in the first few days after birth, as part of their cultural beliefs and practices. ${ }^{4}$ They neglect "COLOSTRUM", instead, infants are given sugar water, plain water, honey, etc. All these practices lead to suppression of lactation, as prolactin gradually ceases and the breast stops secreting milk. ${ }^{4}$ It also risks the infant's health as they become more prone to diarrhea and other infectious diseases due to mixed feeding practices. ${ }^{6}$

In South Asia, only 24-26\% of babies born in India, Pakistan, and, Bangladesh are breastfed within 1 hour while the corresponding rate for Sri Lanka is $75 \%$ and National Family Health Survey (NFHS-3) data show proper initiation \& continuation of breastfeeding in children under 6 months is only $46.4 \% .^{7,8}$ Suboptimal breastfeeding was ranked by the Global Burden of Diseases, Injuries, and, Risk Factor Study to be the second largest risk factor for children under five, accounting for the loss of 47.5 million Disability Adjusted Life Years (DALYs) in 2010..$^{9}$ According to the Lancet's Series on Child Survival, increasing breastfeeding prevalence to optimal levels could reduce $13 \%$ of all child deaths in low income countries. ${ }^{10}$

Despite many awareness programs given to mother regarding benefits of breastfeeding, we still see mothers 
to follow ill breast feeding techniques. Therefore, the present study was undertaken with the objective to assess knowledge, attitude, and, determinants of breastfeeding among antenatal women coming to DM WIMS hospital, Wayanad, Kerala, for antenatal checkup.

\section{Material and Methods}

This study is a cross-sectional descriptive study done in DM WIMS medical college hospital, Wayanad, Kerala, during April-May 2018. All pregnant ladies attending antenatal check-up during this period were included in the study. After obtaining informed consent, a total of 120 women accepted to enter the study. A semi-structured questionnaire containing various aspects of breastfeeding was used. The questionnaire consisted of socio-demographic variables like age, gravida, parity, employment status, type of family, etc. of the participants and 10 questions to assess the knowledge, attitude, and determinants of breastfeeding among them. The study was approved by institutional ethical committee of DM WIMS.

The data was analyzed using SPSS 21 . The results were tabulated and expressed in terms of percentages and proportions pertaining to the questionnaire answered by the study participants. The results are expressed based on the three domains namely attitude, knowledge and determining factors on breastfeeding.

\section{Results}

120 antenatal women were included in the present study. Table 1 gives the background information about study participants. $55.8 \%$ participants were in the age group 18-25yrs. The mean age of study participant was 25.4 years. $22 \%$ of participants were unemployed, whereas, $76 \%$ did not reveal their employment status. $50 \%$ of them were nulliparous, $30 \%$ primiparous and $20 \%$ were multiparous.

Table 1: Background information about participants

\begin{tabular}{|l|l|c|}
\hline Characteristics & \multicolumn{1}{|c|}{ Group } & $\begin{array}{c}\text { Frequency (\%) } \\
\mathbf{n = ( 1 2 0 )}\end{array}$ \\
\hline Age (yrs) & $18-25$ & $67(55.8 \%)$ \\
\cline { 2 - 3 } & $26-40$ & $53(44.2 \%)$ \\
\hline \multirow{2}{*}{$\begin{array}{l}\text { Employment } \\
\text { status }\end{array}$} & Employed & $3(2 \%)$ \\
\cline { 2 - 3 } & Unemployed & $26(22 \%)$ \\
\cline { 2 - 3 } Parity & Not revealed & $91(76 \%)$ \\
\cline { 2 - 3 } & Nulliparous & $61(50 \%)$ \\
\cline { 2 - 3 } & Primiparous & $35(30 \%)$ \\
\cline { 2 - 3 } & Multiparous & $24(20 \%)$ \\
\hline
\end{tabular}

When assessed the knowledge and attitude about breastfeeding, $43.3 \%$ of the study participants knew the importance of breastfeeding (Table 1: Background information about participants). Out of $43.3 \%$ who considered breastfeeding important, $56 \%$ said it is very important (Fig. 1). Only 37.5\% knew about colostrum (Table 2) and 53\% of them considered it very important (Fig. 1). 79\% said breastfeeding is beneficial to both mother and baby and $63 \%$ said that an infant should be breastfed 10-15 times a day (Table 2). $91.6 \%$ of study participants knew the importance of nutritious food intake like green leafy vegetable, milk, iron rich foods, etc during antenatal period and during breastfeeding (Table 2). 93.3\% participants considered breast milk healthier than artificial substitute like formula milk, etc (Fig. 2). Majority of participants received information about breast feeding from media $(54 \%)$ and doctors $(41 \%)$. Other sources of information $(5 \%)$ was from advertisement and government health workers (Fig. 3).

Table 2: Knowledge and attitude about breastfeeding among ante-natal women

\begin{tabular}{|c|l|c|}
\hline SI no & \multicolumn{1}{|c|}{ Question } & Response \\
\hline 1 & Meaning of exclusive breast feeding & $52(43.3 \%)$ \\
\hline 2 & Colostrum & $45(37.5 \%)$ \\
\hline 3 & Correct technique of breast feeding & $113(91 \%)$ \\
\hline 4 & Increase food intake during breast feeding & $110(91.7 \%)$ \\
\hline 5 & Breastfeeding is beneficial to both mother and baby & $95(79 \%)$ \\
\hline 6 & Infant should be breastfed 10-15 times a day & $76(63 \%)$ \\
\hline 7 & Importance of nutritious food intake & $110(91.6 \%)$ \\
\hline
\end{tabular}




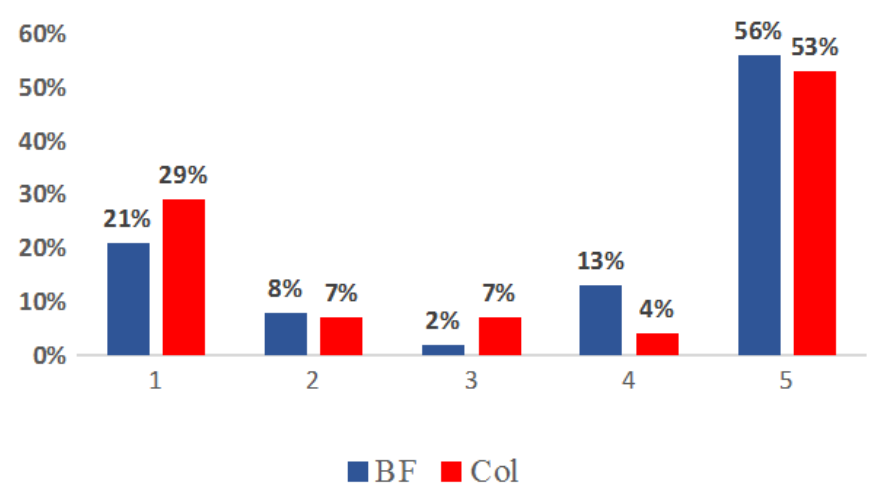

*1: Not at all important; 5: Very important

Fig 1: Importance of exclusive breastfeeding and colostrum

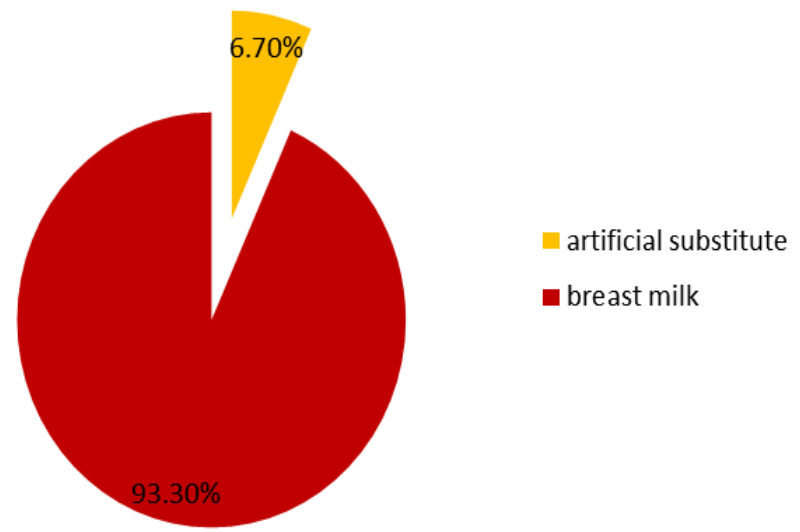

Fig 2: Which is healthy breast milk or artificial substitutes like formula milk, etc??

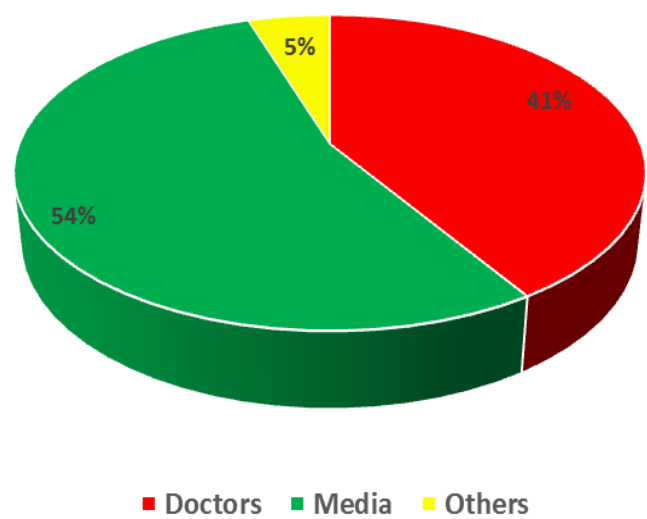

Fig 3: Source of information and knowledge about breastfeeding

Table 3 shows various factors affecting breastfeeding. In the present study, 79\% of study participants believed that during systemic illness they should not breastfeed the infant, $74 \%$ said tension at home can affect milk production and breastfeeding. $72 \%$ said that anxiety affects milk production. $63 \%$ said soreness, tenderness or pain in nipple can affect breastfeeding. $61 \%$ said crèche should be available at work place. $77 \%$ said presence of strangers affect breastfeeding.

Table 3: Factors affecting breastfeeding/ Mothers correct answer about breast feeding knowledge

\begin{tabular}{|c|l|c|}
\hline SI no. & \multicolumn{1}{|c|}{ Items } & Yes \\
\hline 1 & $\begin{array}{l}\text { Soreness/tenderness/pain in the nipple of the mother can affect } \\
\text { breast feeding }\end{array}$ & $76(63 \%)$ \\
\hline 2 & During systemic illness mothers should not breast feed the babies & $95(79 \%)$ \\
\hline
\end{tabular}




\begin{tabular}{|c|l|c|}
\hline 3 & Anxiety can affect breast feeding and milk production & $87(72 \%)$ \\
\hline 4 & $\begin{array}{l}\text { Tension at home /work place can reduce breast milk and affect } \\
\text { breast feeding }\end{array}$ & $89(74 \%)$ \\
\hline 5 & $\begin{array}{l}\text { Depression \& sadness due to family problems does not affect } \\
\text { breast feeding }\end{array}$ & $27(22 \%)$ \\
\hline 6 & Unfamiliar environment affects breast feeding. & $42(35 \%)$ \\
\hline 7 & Presence of strangers affect breast feeding. & $92(77 \%)$ \\
\hline 8 & $\begin{array}{l}\text { Baby nursing rooms/ feeding rooms should be available in all } \\
\text { work places. }\end{array}$ & $67(56 \%)$ \\
\hline 9 & Crèche should be available in all work places & $73(61 \%)$ \\
\hline
\end{tabular}

Table 4 and 5 shows association of age and parity with knowledge of exclusive breast feeding and colostrum. A significant association was seen between age and breastfeeding ( $\mathrm{p}$-value 0.003), and also between, age and knowledge of colostrum ( $\mathrm{p}$-value 0.002). Association between parity and breastfeeding, and, parity and colostrum was also found to be significant in our study with p-value 0.001 and 0.007 respectively.

Table 4: Association between age and parity with knowledge of exclusive breast feeding

\begin{tabular}{|c|c|c|c|c|c|}
\hline \multirow[t]{2}{*}{ Variable } & & \multicolumn{2}{|c|}{$\begin{array}{l}\text { Exclusive breast } \\
\text { feeding }\end{array}$} & \multirow[t]{2}{*}{ Chi sq value } & \multirow[t]{2}{*}{ p-value } \\
\hline & & Yes $(\%)$ & No $(\%)$ & & \\
\hline \multirow{2}{*}{$\begin{array}{l}\text { Age } \\
\text { (in years) }\end{array}$} & $18-25$ & 17.5 & 38.4 & \multirow{2}{*}{8.8} & \multirow{2}{*}{0.003} \\
\hline & $26-40$ & 25.8 & 18.3 & & \\
\hline \multirow{3}{*}{ Parity } & Nulliparous & 12 & 38.8 & \multirow{3}{*}{17.30} & \multirow{3}{*}{0.001} \\
\hline & Primiparous & 12.5 & 16.7 & & \\
\hline & Multiparous & 15.8 & 4.2 & & \\
\hline
\end{tabular}

$*$ p-value $<0.05$ is significant

Table 5: Association between age and parity with knowledge of colostrum

\begin{tabular}{|c|c|c|c|c|c|}
\hline \multirow{2}{*}{ Variable } & & \multicolumn{2}{|c|}{ Colostrum } & \multirow[t]{2}{*}{ Chi sq value } & \multirow{2}{*}{ p-value } \\
\hline & & Yes $(\%)$ & No $(\%)$ & & \\
\hline Age & $18-25$ & 14.2 & 41.7 & \multirow{2}{*}{9.51} & \multirow{2}{*}{0.002} \\
\hline (in years) & $26-40$ & 23.3 & 20.8 & & \\
\hline & Nulliparous & 13.3 & 37.5 & \multirow{3}{*}{9.79} & \multirow{3}{*}{0.007} \\
\hline Parity & Primiparous & 11.7 & 17.5 & & \\
\hline & Multiparous & 12.5 & 7.5 & & \\
\hline
\end{tabular}

$*$ p-value $<0.05$ is significant

\section{Discussion}

Benefits of breastfeeding extend beyond basic nutrition. It has both immunological and antiinflammatory properties, which protect both mother and infant, against a host of illness and diseases. ${ }^{11}$ There are a lot of misconceptions, customs and pseudo beliefs regarding breastfeeding practices, which are being followed from generations in many countries. These practices have often affected both the mother and infant. In the present study, we have tried to assess the knowledge and attitude of participants (ante-natal women) of Wayanad district, Kerala. 120 participants were included in this study. $55.8 \%$ participants were in the age group 18-25yrs. The mean age of study participant was 25.4 years. $76 \%$ of participants did not reveal their employment status. Only $2 \%$ of the study participants were working. 50\% of the participants were nulliparous.

In this study, we assessed knowledge and attitude towards exclusive breastfeeding and found that only $43.3 \%$ of the study participants knew the importance of breastfeeding. Of them, $56 \%$ believes it is very important, whereas $21 \%$ believes it is not at all important. Only $37.5 \%$ knew about colostrum and 53\% of them considers it very beneficial for baby. Victor Mogre et al, in their study found that $58 \%$ of the mothers practiced exclusive breastfeeding. ${ }^{9}$ In another study by SB Shetty et al, done in the coastal town of South India, they found that $58.7 \%$ knew the importance of breastfeeding. ${ }^{12}$ Chaudhary et al in another study reported that only $25 \%$ of mothers recognized the importance of colostrum. ${ }^{13}$ In contrast, data in few studies show that the knowledge of mother's about exclusive breastfeeding and colostrum was very high (70-97\%) compared to present study. ${ }^{14-18}$

The prevalence of exclusive breastfeeding found in the present study is below the WHO recommended prevalence of $90 \% .{ }^{10}$ This shows an extensive 
difference between the desired and the actual practice of exclusive breastfeeding. The difference could be due to lack of knowledge, social norms, poor family and social support, embarrassment, lactation problems, employment and child care and barriers related to health services. ${ }^{19,20}$ Educating mothers and emphasizing on various advantages of exclusive breastfeeding can help in overcoming this gap of knowledge and practice. Family members, health professionals and media play an important role in spreading awareness and knowledge about exclusive breastfeeding. In the present study, only $41 \%$ of participants considered doctors to be the main source of knowledge about breastfeeding, whereas, $54 \%$ of participants considered media as the main source.

The attitude of mothers towards breastfeeding revealed that majority of mothers had positive perspective towards breastfeeding. In the present study, $79 \%$ of participants said breastfeeding is beneficial to both mother and baby, and $63 \%$ said that an infant should be breastfed 10-15 times a day. 93.3\% participants considered breast milk healthier than artificial substitute like formula milk, etc. Our result was higher than in the study by Al-Binali et al $(36.7 \%)^{21}$ and Khamnianet $\mathrm{al}(31 \%) .^{22} \quad 79 \%$ of participants in our study presume that during systemic illness they should not breastfeed the infant, 74\% thought tension at home can affect milk production and breastfeeding, $72 \%$ said that anxiety affects milk production, and, $63 \%$ said soreness, tenderness or pain in nipple can affect breastfeeding. There are various studies supporting the same views by mother. Similar findings has been reported in many studies. ${ }^{23,24}$ These are negative and unfavorable assumptions, which leads to an abrupt cessation of breastfeeding which can be overcome by continuous health education of mother. ${ }^{24}$

Another very important social barrier to breastfeeding is employment. Lack of privacy and unsupportive work environments usually lead to early cessation of breastfeeding. $61 \%$ of participants in the present study said that crèche should be available at workplace, $56 \%$ said baby nursing rooms/ feeding rooms should be available in all workplaces, $35 \%$ said unfamiliar environment affects breastfeeding and 77\% said that presence of strangers affect breast feeding. Therefore, support in the workplace with little adjustments and rearrangement will make it easier for women employees to continue breastfeeding for the best health interests of mother and child.

The present study reveals, there is a significant association between age and parity with knowledge of exclusive breast feeding and colostrum. $25.8 \%$ of women between 26-40yrs knew about exclusive breastfeeding, compared to, $17.5 \%$ of women between 18-25 yrs (p-value 0.003). 23.3\% of women between 26-40 yrs knew about colostrum, compared to, $14.2 \%$ women between 18-25 yrs (p-value 0.002). Similar findings were reported in various studies. ${ }^{25-28}$ We also found a significant aassociation between parity and breastfeeding, and, parity and colostrum, with p-value 0.001 and 0.007 respectively.

\section{Conclusion}

Breastfeeding gives children the healthiest start in life and is one of the simplest, smartest and most costeffective ways we have of ensuring that all children survive and thrive. Present study showed satisfactory knowledge and attitude of mother's towards exclusive breastfeeding. To further increase the breastfeeding practices, mothers, especially nulliparous and young mothers, should be educated about the benefits and importance of exclusive breast-feeding during their ante-natal visits. The main limitation of the present study is- small sample size. Further studies are needed with larger population.

Funding: No funding sources.

Conflict of interest: None declared.

\section{References}

1. Motee A, Jeewon R. Importance of exclusive breastfeeding and complementary feeding among infants. Curr Res Nutrition Food Sci J 2014;28;2(2):56-72.

2. Ghai, O.P., Paul, V.K. and Bagga, A. (2009) Textbook of Paediatrics. 7th Edition, CBC Publisher and Distributors, New Delhi, 768.

3. Palmeira P, Carneiro-Sampaio M. Immunology of breast milk. Revista da Associação Médica Brasileira. 2016;62 (6):584-93.

4. Shewasinad S, Manjura M, Bolesh A, Sisay D, Negash S (2017) Assessment of Knowledge, Attitude and Practice Towards Colostrum Feeding Among Antenatal Care Attendant Pregnant Mothers in Mizan Tepi University Teaching Hospital, Bench Maji Zone, SNNPR, South West Ethiopia, 2016/2017 G.C. J Preg Child Health 4:348. doi: $10.4172 /$

5. Kumari S, Saili A, Jain S, Rhargava U, Gandhi G, Seth P. Maternal attitude and practices in initiation of newborn feeding. Indian J Pediatr 1988;55(6):905-11. 2376127X.1000348

6. https://www.unicef.org/nutrition/index_24824.html

7. Vinay BS, Sandeep M, Sridhar PV. Assessment of knowledge, attitude and practice of breast feeding among postnatal mothers at Mandya Institute of Medical Sciences, Mandya, India. Int J Contemporary Pediatr 2016;3 (2):504-8.

8. The state of the world's breastfeeding: report card. Initiation of breastfeeding within 1 hour. New Delhi: International Baby Food Action Network Asia. Available at: http://www.worldbreastfeedingtrends.org/reportcard/RCIB.pdf.

9. Mogre V, Dery M, Gaa PK. Knowledge, attitudes and determinants of exclusive breastfeeding practice among Ghanaian rural lactating mothers. Int breastfeeding $J$ 2016;11(1):12.

10. Jones G, Steketee RW, Black RE, Bhutta ZA, Morris SS, Bellagio Child Survival Study Group. How many child deaths can we prevent this year? Lancet 2003;362(9377):65-71.

11. Palmeira P, Carneiro-Sampaio M. Immunology of breast milk. Revista da Associação Médica Brasileira. 
2016;62(6):584-93.

12. Shetty SB, Shetty SK. KAP study of factors promoting breastfeeding in nursing mothers and pregnant women. NUJHS 2013;3(3):34-7.

13. Chaudhary RN, Shah T, Raja S. Knowledge and practice of mothers regarding breast feeding: a hospital based study. Health Renaissance 2011;9(3):194-200.

14. Deepanjan Ray, Abdur Rahaman, Aparajita Dasgupta. Breastfeeding Knowledge among Antenatal Mothers: A CrossSectional Study in a Rural Area of West Bengal. IOSR J Dent Med Sci (IOSR-JDMS). 2015;14(5):93-97.

15. Galhotra A, Abrol A, Agarwal N, Goel N, Swami H. Impact of community based awareness campaign on breast-feeding among lactating women in Chandigarh. Internet J Health 2008;7(1).

16. Girish HO, Acharya A, Kumar A, Venugopalan PP, Prabhakaran S, Koppad R. Knowledge and practices of breastfeeding among ante-natal mothers at a Teaching Hospital at Kannur, Kerala: a cross-sectional study. $J$ Evolution Med Dent Sci 2013;2(46):8996-9002.

17. Kulkarni J, Rekahde N, Sharma S. Knowledge and practice of mothers about breast feeding. [online]. [cited 2013 Oct 12]. Available from: URL:

http://www.ssmrae.com/admin/images/0a0b27357895a5b 82567fcabc36c0850.pdf

18. Joshi S, Barakoti B, Lamsal S. Colostrum Feeding: Knowledge, Attitude and Practice in Pregnant Women in a Teaching Hospital in Nepal. Webmed Central: Int J Med Molecular Med 2012;3(8):WMC003601

19. McGuire S. US Dept. of Health and Human Services. The Surgeon General's Call to Action to Support Breastfeeding. US Dept. of Health and Human Services, Office of the Surgeon General. 2011.

20. Abdulsalam Mohammed Dallak, Nabil Ahmed Al-Rabeei, Yassein Ahmed Aljahmi. Breastfeeding Knowledge, Attitude, and Practices among Mothers Attending Health Centers in Sana'a City. ARC Journal of Public Health and Community Medicine 2016;1(2):9-17

21. Al-Binali AM. Breastfeeding knowledge, attitude and practice among school teachers in Abha female educational district, southwestern Saudi Arabia. Int
Breastfeeding J 2012;7(1):10.

22. Z. Khamnian, A. Azarfar, Y. Ravanshad, M. Hashemian and K. Hasanpour. Exclusive Breastfeeding and Factors Affecting Knowledge, Attitude and Practice of Mothers in Rural and Urban Regions of East Azerbaijan, Iran. 2013. Life Sci J 10(5s)473-78,

23. Mohammed ES, Ghazawy ER, Hassan EE. Knowledge, attitude, and practices of breastfeeding and weaning among mothers of children up to 2 years old in a rural area in El-Minia governorate, Egypt. J Family Med Primary Care 2014;3(2):136.

24. Kishore K. Knowledge, Attitude and Practices of weaning among mothers in Gulbarga, MD thesis; Department of Pediatrics, MR Medical College, Gulbarga, Ranjiv Gandhi University of Health Sciences; Karnataka, Bangalore. 2008:1-71.

25. Narayan S, Natarajan N, Bawa KS. Maternal and Neonatal Factors Adversely Affecting Breastfeeding in the Perinatal Period. Med J Armed Forces Ind 2005;61:21619.

26. Scott JA, Aitkin I, Binns CW, Aroni RA. Factors associated with the duration of breastfeeding amongst women in Perth, Australia. Acta Paediatr 1998;88(4):416-21.

27. Feinstein JM, Berkelhamer JE, Gruszka ME, Wong CA, Carey AE. Factors Related to Early Termination of Breast-Feeding in an Urban Population. Pediatr 1986;78 (2): 210-15.

28. Michaelsen KF, Larsen PS, Thomsen BL, Samuelson G. The Copenhagen cohort study on infant nutrition and growth: duration of breast feeding and influencing factors. Acta Pcediatr 1994;83:565-71.

How to cite the article: Narayana M., Mithrason A, Thomas V. Knowledge, attitude and determinants of breastfeeding among ante-natal women at a teaching hospital at Wayanad, Kerala: A cross-sectional study. IP Int J Med Paediatr Oncol 2018;4(3):98-103. 